\title{
Pengaruh Penyuntikan Ekstrak Kelenjar Hipofisa Ayam Broiler Terhadap Pemijahan Ikan Lele Dumbo (Clarias gariepinus Burchell)
}

\author{
Azhar dan Masrizal \\ Jurusan Produksi Temak Fakultas Petemakan Universitas Andalas, Padang
}

\begin{abstract}
The objectives of this experiment was to study the effect of chicken hypopinyse gland extract for spanwing of cat fish. Each twenty four female and male cat fishes of about $1000-1050 \mathrm{~g}$ body weighthead were used in the experiments. Hypophyse gland extract were prepared from the hypophyse glands of broiler chickens. As treaments, the extract were injected in sir different doses of $300,400,500,600,700$ and $800 \mathrm{mg} / \mathrm{kg}$ body weight. Each doses was injected twice. The second injection were done after 4 hours. Each treatment consisted of 4 replications as bloct. Parameter measured included: spawning latent time, ovulation and egg maturation degree, water qualitiesftemperature, dissolved $\mathrm{O}_{2}$ free $\mathrm{CO}_{2}, \mathrm{NH}_{3}$ content and $\mathrm{pH}$ ). Data were statistically anolyzed by variance analysis in randomized block design (RBD), Results indicated that injection of broiler's hypophyse gland extract gave highty significant $(P<0.01$ ) effect on the acceleration of sponining latent time (10 hrs). increase of percentage of ovulation (84.32 \%) and egg maturation degree $(89,94 \%$ ). The optimal injection dose was found 741,95 mg brotter's hypophse gland $\mathrm{kg}$ catfish body' weight.
\end{abstract}

Key words: broilers' hypophysisi gland, cat fish breuding.

\section{Pendahuluan}

Ikan lele dumbo (Clarias gariepinus Burchell) adalah merupakan salah satu jenis ikan air tawar yang sudah bisa dibudidayakan. Bila dibandingkan dengan jenis ikan air tawar lainnya, ikan lele dumbo memiliki beberapa keunggulan yaitu pertumbuhannya yang sangat cepat, mudah dipelihara, tahan terhadap kondisi air yang buruk, memiliki nilai gizi dan nilai ekonomis yang cukup tinggi.

Dalam usaha budidaya ikan lele dumbo, ketersediaan benih dalam kualitas dan kuantitas yang cukup merupakan faktor mutlak yang sangat menentukan keberhasilan usaha. Untuk mendapatkan benih yang berkualitas baik dalam jumlah yang cukup dan berkesinambungan, haruslah melalui pembenihan secara terkontrol yaitu dengan melakukan pemijahan secara buatan (induced breeding) yang diikuti dengan pembuahan buatan (artificial fertilization).

Dalam melakukan pemijahan secara buatan, teknik yang sering digunakan adalah teknik hipofisasi. Hipofisasi adalah merupakan usaha untuk merangsang ikan yang matang kelamin untuk ovulasi dan memijah melalui penyuntikan dengan ekstrak kelenjar hipofisa. Hardjamulia dan Atmawinata (1980) mengemukakan bahwa teknik hipofisasi pada ikan dilakukan dengan menggunakan hipofisa ikan, baik hipofisa ikan 
yang sejenis maupun yang tidak sejenis antara donor (ikan yang diambil hipofisanya) dan resipient (ikan yang disuntik).

Walaupun telah ditemukan teknik hipofisasi yang dapat memijahkan (mengawinkan) ikan setiap saat, namun para petani ikan lebih suka memijahkan ikan lele dumbo secara alami. Hal ini disebabkan karena pada teknik hipofisasi, para petani ikan harus mengorbankan ikan lain untuk dijadikan sebagai donor hipofisa dan ini merupakan kelemahan teknik hipofisasi. Untuk itu maka perlu dicobakan kelenjar hipofisa hewan lain diantaranya kelenjar hipofisa ayam broiler. Disamping murah, kelenjar hipofisa ayam broiler mudah sekali didapatkan, karena kelenjar hipofisa ayam broiler ini terbuang percuma sebagai limbah bersama tulang tengkorak kepala ayam di pasar-pasar tempat pedagang memotong dan menjual ayam broiler.

Tujuan dari penelitian ini adalah untuk mengetahui hasil pemijahan (waktu laten pemijahan. ovulasi dan tingkat kematangan telur) ikan lele dumbo yang dipijahkan dengan teknik hipofisasi yang menggunakan kelenjar hipofisa ayam broiler. Dari hasil penelitian ini diharapkan akan dapat ditemukan dosis penyuntikan kelenjar hipofisa ayam broiler yang optimal untuk merangsang pemijahan induk ikan lele dumbo dengan menggunakan teknik hipofisasi.

\section{Metode Penelitian}

Penelitian ini dilakukan dari tanggal 2 Juni sampai 24 Agustus 2005, yaitu di Balai Benih Ikan Kiambang Kecamatan 2 × 11 Enam Lingkung, Kabupaten Padang Pariaman, Propinsi Sumatera Barat.
Ikan uji yang digunakan dalam penelitian ini adalah 24 ekor ikan lele dumbo betina dan 24 ekor ikan lele dumbo jantan yang matang gonad dengan berat masingmasingnya antara $1,000 \sim 1,050 \mathrm{~kg} /$ ekor. Untuk kelenjar hipofisa digunakan kelenjar hipofisa ayam broiler yang diambil dari kepala ayam broiler berumur 40 hari.

Rancangan yang digunakan dalam penelitian ini adalah Rancangan Acak Kelompok (RAK), yang terdiri dari enam taraf perlakuan dan setiap taraf perlakuan terdiri atas empat kelompok yang berdasarkan kepada waktu pelaksanaan ulangan penelitian (Steel dan Torrie, 1989). Adapun perlakuan dalam penelitian ini adalah dosis penyuntikan kelenjar hipofisa ayam broiler yang terdiri dari enam taraf yaitu : $300\left(\mathrm{P}_{1}\right), 400\left(\mathrm{P}_{2}\right), 500\left(\mathrm{P}_{3}\right)$, $600\left(\mathrm{P}_{4}\right) .700\left(\mathrm{P}_{5}\right)$ dan $800\left(\mathrm{P}_{6}\right) \mathrm{mg}$ kelenjar hipofisa ayam boiler/kg ikan lele dumbo.

Penyuntikan ekstrak kelenjar hipofisa ayam broiler ini dilakukan sebanyak dua kali. dimana penyuntikan pertama adalah sebanyak sepertiga dari dosis perlakuan, dan setelah empat jam kemudian dilakukan pula penyuntikan ke dua yaitu sebanyak dua pertiga dosis perlakuan. Setelah itu induk ikan lele dumbo betina dibiarkan dalam bak pemijahan sampai terlithat tandatanda terjadinya ovulasi atau pemijahan.

Peubah yang diamati dalam penelitian ini adalah waktu laten pemijahan, ovulasi dan tingkat kematangan ikan lele dumbo. Selain itu dilakukan pula pengukuran parameter kualitas air yang meliputi suhu, oksigen $\left(\mathrm{O}_{2}\right)$ terlarut. karbondioksida $\left(\mathrm{CO}_{2}\right)$ bebas, 
amoniak $\left(\mathrm{NH}_{3}\right)$ dan derajat keasaman $(\mathrm{pH})$.

Data hasil penelitian dianalisis dengan unalisis ragam berdasarkan Rancangan Acak Kelompok (Steel dan Torrie, 1989). Uji lanjut dilakukan dengan uji wilayah berganda duncan, dan disamping itu dilakukan pula uji polinomial orthogonal (Sudjana, 1988) yaitu untuk menentukan dosis penyuntikan ekstrak kelenjar hipofisa ayam broiler yang optimal.

\section{Hasil Dan Pembahasan}

\section{Waktu Laten Pemijahan}

Berdasarkan hasil pengamatan selama penelitian didapatkan bahwa penyuntikan kelenjar hipotisa ayam broiler dengan dosis berbeda memberikan waktu laten pemijahan ikan lele dumbo yang berbeda pula, seperti yang terlihat pada Tabel I di bawah ini. Pada Tabel I terlihat bahwa waktu laten pemijahan ikan lele dumbo tercepat terdapat pada perlakuan dengan penyuntikan 600 mg kelenjar hipofisa ayam broiler $/ \mathrm{kg}$ ikan lele dumbo $\left(\mathrm{P}_{4}\right)$ yaitu 10,00 jam. Sedangkan yang terlama terdapat pada perlakuan dengan penyuntikan $300 \mathrm{mg}$ kelenjar hipofisa ayam broilerikg ikan lele dumbo $\left(P_{1}\right)$ yaitu 14,31 jam.

Hasil analisis ragam menunjukan bahwa penyuntikan kelenjar hipofisa ayam broiler dengan dosis yang berbeda memberikan pengaruh yang sangat nyata $(\mathrm{P}<0,01)$ terhadap waktu lafen pemijahan ikan leke dumbo. Kemudian hasil uji lanjut wilayah berganda duncan menunjukan pula bahwa waktu laten pemijahan dari ikan lele dumbo yang disuntik dengan $600 \mathrm{mg}$ kelenjar hipofisa ayam broiler/kg berat ikan lele dumbo $\left(\mathrm{P}_{4}\right)$ sangat nyata $(\mathrm{P}<0,01)$ lebih cepat bita dibandingkan dengan ikan lele dumbo yang disuntik dengan $800 \mathrm{mg}\left(\mathrm{P}_{6}\right), 700 \mathrm{mg}\left(\mathrm{P}_{5}\right)$, $500 \mathrm{mg}\left(\mathrm{P}_{3}\right), 400 \mathrm{mg}\left(\mathrm{P}_{2}\right)$ dan 300 $\mathrm{mg}$ kelenjar hipofisa ayam broiler/kg berat ikan lele dumbo $\left(\mathrm{P}_{\mathrm{i}}\right)$.

Hasil uji polinomial orthogonal menunjukan bahwa hubungan antara dosis penyuntikan kelenjar hipofisa ayam broiler dengan waktu laten pemijahan ikan lele dumbo adalah kuadtratik dengan persamaan regresinya : $\hat{\mathrm{Y}}=21,1483$ $-0.0292 X+1.96 .10^{-5} X^{2}$, dimana $\hat{Y}=$ waktu laten pemijahan dugaan (jam), dan $X=$ dosis penyuntikan kelenjar hipofisa ayam broiler ( $\mathrm{mg}$ kelenjar hipofisa ayam broiler/kg berat ikan lete dumbo). Berdasarkan persamaan regresi ini didapatkan bahwa dosis penyuntikan kelenjar hipofisa ayam broiler yang optimal adalah $744,90 \mathrm{mg}$ kelenjar hipofisa ayam broiler/kg berat ikan lele dumbo dengan waktu laten pemijahan dugaan minimal 10,27 jam. Untuk lebih jelasnya dapat dilihat pada Gambar 1.

Dari grafik yang terdapat pada Gambar 1. terlihat bahwa semakin tinggi dosis penyuntikan kelenjar hipofisa ayam broiler, maka waktu laten pemijahan ikan lele dumbo akan semakin cepat. Hal ini disebabkan karena semakin tingginya kandungan hormon LH (Luteinizing Hormon) di dalam darah ikan lele dumbo akibat dari penyuntikan kelenjar hipofisa ayam broiler. Dengan semakin tingginya hormon LH dalam darah ikan lele dumbo yang diperlakukan, menyebabkan semakin cepatnya pula proses ovulasi terjadi. sehingga waktu laten pemijahan semakin cepat pula. Seperti yang telah dikemukakan oleh Sturkie (1976) bahwa kelenjar 
hipofisa ayam broiler mengandung berbagai jenis hormon diantaranya adalah hormon LH (Luteinizing Hormon). Kemudian Lam (1982) dan Matty (1985) menambahkan bahwa hormon LH berfungsi merangsang proses ovulasi dan pemijahan induk ikan betina. Kemudian grafik pada Gambar 1 memperlihatkan pula bahwa pada dosis penyuntikan yang lebih tinggi dari $744,90 \mathrm{mg}$ kelenjar hipofisa ayam broiler/kg berat ikan lele dumbo, waktu laten pemijahan ikan lele dumbo semakin lama. Hal ini diduga karena terjadinya over dosis yang menyebabkan terganggunya sistem kerja hormon dalam proses ovulasi tersebut. Menurut Bardach et. al., (1972) kelebihan dosis kelenjar hipofisa dalam teknik hipofisa dapat membuat ikan tidak memijah atau kembali sama seperti pada tingkat gonad belum matang (premature).

Seperti yang telah dikemukakan oleh Sturkie (1976) bahwa kelenjar hipofisa ayam broiler mengandung berbagai jenis hormon diantaranya adalah hormon LH (Luteinizing Hormon). Kemudian Lam (1982) dan Matty (1985) menambahkan bahwa hormon LH berfungsi merangsang proses ovulasi dan pemijahan induk ikan betina.

Tabel 1. Waktu Laten Pemijahan (Jam) Ikan Lele Dumbo Pada Masing-Masing Perlakuan Dan Kelompok.

\begin{tabular}{|c|c|c|c|c|c|c|}
\hline \multirow{2}{*}{ Kelompok } & \multicolumn{6}{|c|}{ Perlakuan ( mg kelenjar hipeflsa ayam broiter / kg itian lele dumbo ) } \\
\hline & $P_{1}(300)$ & $\mathrm{P}_{2}(400)$ & $P_{3}(500)$ & $P_{4}(600)$ & $P_{s}(700)$ & $P_{6}(800)$ \\
\hline 1 & 14.50 & 12,50 & 11,25 & 10.25 & 10,50 & 10,50 \\
\hline 2 & 14.75 & 12,75 & 11,75 & 10,25 & 10,75 & 11,00 \\
\hline 3 & 13,75 & 11,75 & 10.75 & 9.50 & 9.75 & 10,00 \\
\hline 4 & 14,25 & 12,25 & 11,00 & 10,00 & 10,00 & 10,25 \\
\hline Jumlah & 57,25 & 49.25 & 44.75 & 40,00 & 41.00 & 41.75 \\
\hline Rata-rata & $14,31^{x}$ & $12.31^{\mathrm{a}}$ & $11.19^{\mathrm{C}}$ & $10.00^{\mathrm{E}}$ & $10,25^{\mathrm{Dh}}$ & $10,44^{m}$ \\
\hline
\end{tabular}

Tabel 2. Prosentase Ovulasi Ikan Lele Dumbo Pada Masing-Masing Perlakuan Dan Kelompok.

\begin{tabular}{|c|c|c|c|c|c|c|}
\hline \multirow[t]{2}{*}{ Kelompok } & \multicolumn{6}{|c|}{ Perlakuan ( mg kelenjar bipofisa ayam broller / $\mathrm{kg}$ ikan lele dumbo) } \\
\hline & $P_{1}(\mathbf{3 0 0})$ & $P_{2}(400)$ & $P_{3}(500)$ & $P_{4}(600)$ & $P_{0}(700)$ & $P_{6}(800)$ \\
\hline 1 & 63,28 & 71,53 & 76,07 & 80,75 & 82,15 & 83,02 \\
\hline 2 & 65,81 & 69,50 & 78,29 & 83,11 & 79,82 & 86,34 \\
\hline 3 & 60,12 & 76,09 & 80,07 & 85,00 & 87,38 & 78.87 \\
\hline 4 & 61,87 & 73,16 & 83,27 & 88,40 & 84,02 & 81.18 \\
\hline Jumlah & 251.08 & 290,28 & 317.70 & 337,26 & 333,37 & 329,41 \\
\hline Rata-rata & $62,77^{\wedge}$ & $72,57^{B}$ & $79,43^{C}$ & $84,32^{\mathrm{C}}$ & $83,34^{\mathrm{C}}$ & $82,35^{c}$ \\
\hline
\end{tabular}




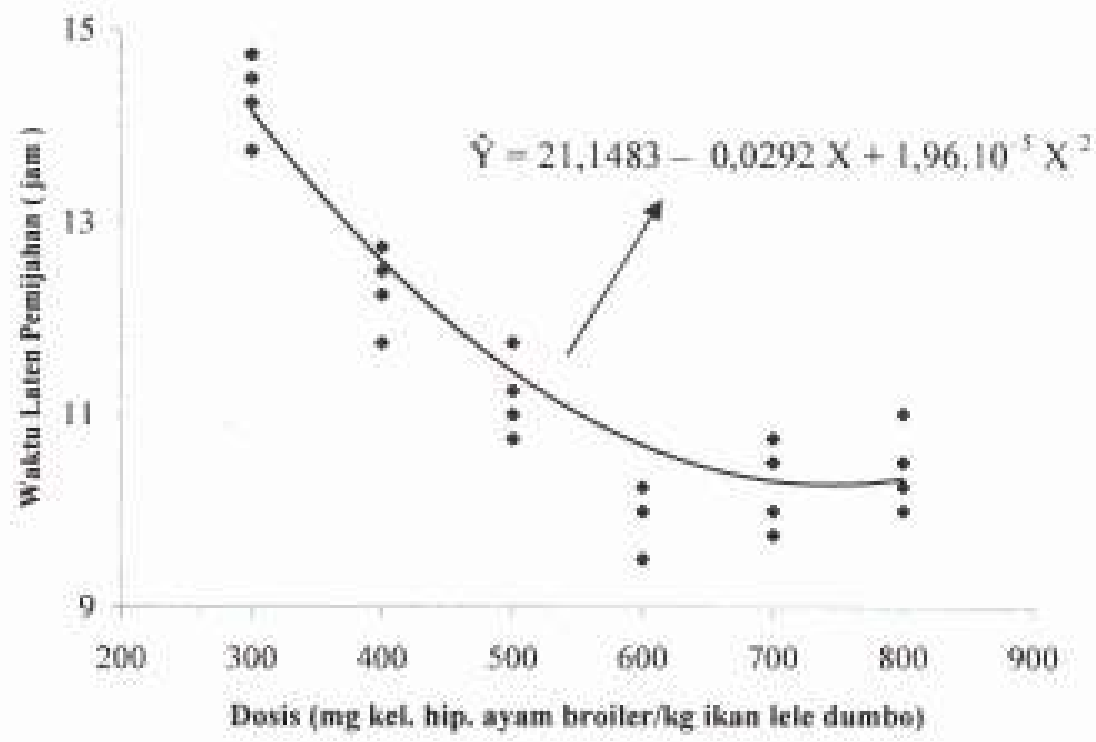

Gambar 1. Grafik hubungan antara dosis penyuntikan kelenjar hipofisa ayam broiler $(\mathrm{X})$ dengan waktu laten pemijahan ikan lele dumbo $(\mathrm{Y})$.

\section{Ovulasi}

Hasil pengamatan terhadap prosentase ovulasi ikan lele dumbo pada masing-masing perlakuan dan ulangan (kelompok) dapat dilihat pada Tabel 2. Dari Tabel 2 terlihat bahwa prosentase ovulasi tertinggi terdapat perlakuan dengan penyuntikan $600 \mathrm{mg}$ kelenjar hipofisa ayam broiler $/ \mathrm{kg}$ berat ikan lele dumbo $\left(\mathrm{P}_{4}\right)$ yaitu $84,32 \%$. Sedangkan yang terendah adalah $62,77 \%$ yaitu terdapat pada perlakuan dengan penyuntikan 300 $\mathrm{mg}$ kelenjar hipofisa ayam broiler $/ \mathrm{kg}$ ikan lele dumbo $\left(\mathrm{P}_{1}\right)$.

Setelah dilakukan analisis ragam, ternyata bahwa penyuntikan kelenjar hipofisa ayam broiler dengan dosis yang berbeda memberikan pengaruh yang sangat nyata terhadap prosentase ovulasi ( $\mathrm{P}$ $<0,01$ ). Kemudian hasil uji lanjut wilayah berganda duncan menunjukan pula bahwa prosentase ovulasi ikan lele dumbo yang disuntik dengan $600 \mathrm{mg}$ kelenjar hipofisa ayam broiler $/ \mathrm{kg}$ ikan lele dumbo $\left(\mathrm{P}_{4}\right)$ sangat nyata $(\mathrm{P}<0,01)$ lebih tinggi bila dibandingkan dengan ikan lele dumbo yang disuntik dengan $300 \mathrm{mg}\left(\mathrm{P}_{1}\right)$, dan $400 \mathrm{mg}$ kelenjar hipofisa ayam broiler $/ \mathrm{kg}$ berat ikan lele dumbo $\left(\mathrm{P}_{2}\right)$, tetapi tidak berbeda nyata $(\mathrm{P}>0,05)$ dengan prosentase ovulasi telur ikan lele dumbo yang disuntik dengan 800 $\mathrm{mg}\left(\mathrm{P}_{6}\right), 700 \mathrm{mg}\left(\mathrm{P}_{5}\right)$, dan $500 \mathrm{mg}$ $\left(\mathrm{P}_{3}\right)$ kelenjar hipofisa ayam broiler/kg ikan lele dumbo.

Dari hasil uji polinomial orthogonal yang telah dilakukan didapatkan bahwa hubungan antara dosis penyuntikan kelenjar hipofisa ayam broiler dengan prosentase ovulasi ikan lele dumbo adalah kuadratik dengan persamaan regresinya sebagai berikut : $\hat{\mathrm{Y}}=$ $27,5556+0,1503 X-0,0001 X^{2}$, dimana $\hat{Y}=$ prosentase ovulasi ikan lele dumbo dugaan dan $\mathrm{X}=$ dosis 
penyuntikan kelenjar hipofisa ayam broiler ( $\mathrm{mg}$ kelenjar hipofisa ayam broiler/kg ikan lele dumbo). Berdasarkan persamaan regresi ini didapatkan bahwa dosis penyuntikan kelenjar hipofisa ayam broiler yang optimal adalah $751,50 \mathrm{mg}$ kelenjar hipofisa ayam broiler $/ \mathrm{kg}$ berat ikan lele dumbo dengan prosentase ovulasi dugaan maksimal $84,03 \%$. Untuk lebih jelasnya dapat dilihat pada Gambar 2.

Dari Gambar 2 terlihat bahwa semakin tinggi dosis penyuntikan kelenjar hipofisa ayam broiler, maka prosentase ovulasi ikan lele dumbo juga semakin meningkat. Hal ini disebabkan karena semakin tingginya konsentrasi hormon LH dalam tubuh ikan lele dumbo akibat dari penyuntikan kelenjar hipofisa ayam broiler tersebut. Dengan semakin tingginya kandungan hormon $\mathrm{LH}$ dalam tubuh ikan lele dumbo mengakibatkan semakin tinggi pula rangsangan yang diterima oleh gonad untuk melakukan ovulasi. Seperti yang telah dikemukakan oleh Lam (1982) dan Matty (1985) bahwa hormon LH berfungsi merangsang proses ovulasi dan pemijahan pada induk ikan betina. Kemudian Aspey (1982) dan Reich et al., (1985) dalam .Jones (1987) mengemukakan pula bahwa hormon LH berfungsi merangsang pelepasan plasminogen aktivator dari sel granulosa. Setelah sekresi plasminogen aktivator meninggi, maka plasminogen dari cairan folikel dan cairan ekstra seluler edema dirombak menjadi plasmin. Plasmin ini akan mengaktitkan laten collagenase pada dinding collagen folikel yang menghasilkan collagenase. Collagenase ini akan memecah collagen, sehingga terjadi pembebasan telopeptida collagen. Telopeptida collagen ini akan menekan dinding folikel sehingga pecah dan terjadi ovulasi. Sedangkan pada dosis penyuntikan kelenjar hipofisa ayam broiler yang lebih tinggi dari dosis optimal, prosentase ovulasi ikan lele dumbo menurun. Ini diduga karena terjadinya over dosis, sehingga menyebabkan proses ovulasi yang dirangsang oleh hormon LH menjadi terganggu.

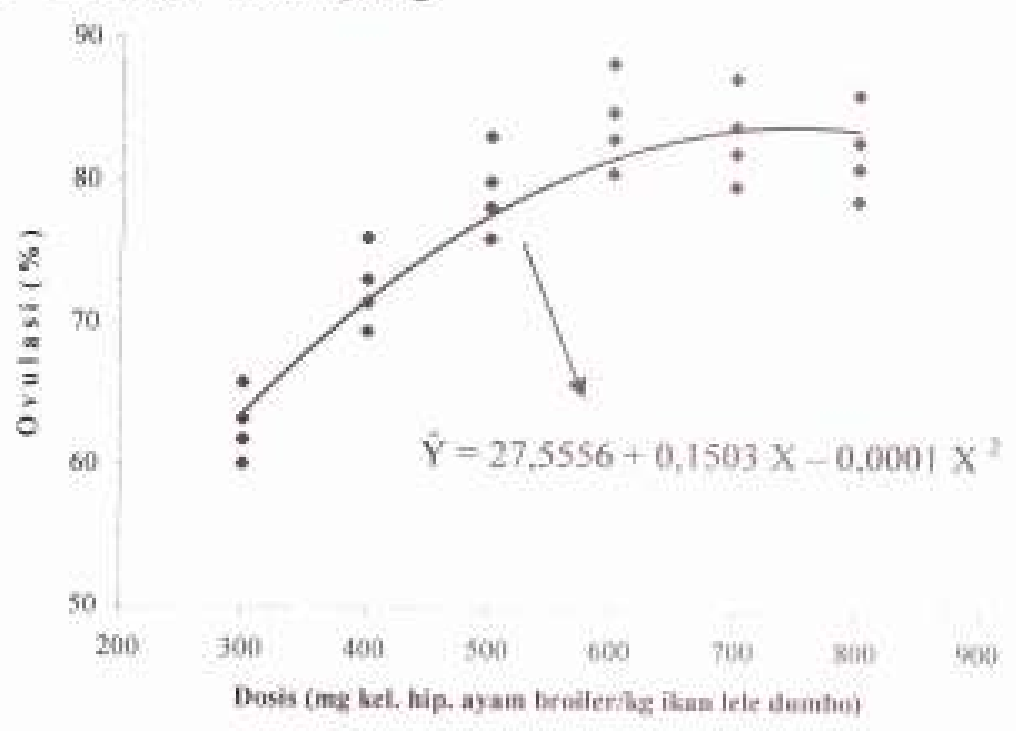

Gambar 2. Grafik hubungan antara dosis penyuntikan kelenjar hipofisa ayam broiler $(X)$ dengan prosentase ovulasi ikan lele dumbo (Y). 


\section{Tingkat Kematangan Teiur}

Telur-telur yang mengalami kematangan tahap akhir ditandai dengan posisi inti sel telur yang telah menepi dan meleburnya membrane inti sel telur. Sedangkan telur yang masih dalam fase dorman atau belum mengalami kematangan tahap akhir ditandai dengan posisi inti sel telur yang masih berada di tengah. Hasil pengamatan terhadap prosentase tingkat kematangan telur sebagai akibat penyuntikan kelenjar hipofisa ayam broiler dengan dosis yang berbeda dapat dilihat pada Tabel 3 .

$$
\text { Bila dilihat Tabel } 3 \text {, }
$$
didapatkan bahwa prosentase tingkat kematangan telur ikan lele dumbo yang tertinggi terdapat pada perlakuan dengan penyuntikan 600 mg kelenjar hipofisa ayam broiler/kg ikan lele dumbo $\left(\mathrm{P}_{4}\right)$ yaitu $89,94 \%$. Sedangkan yang terendah terdapat pada perlakuan $\mathrm{P}_{1}$ (300 mg kelenjar hipofisa ayam broiler/kg ikan lele dumbo) yaitu dengan prosentase tingkat kematangan ikan lele dumbo $73,89 \%$.

Setelah dilakukan analisis ragam terlihat bahwa penyuntikan kelenjar hipofisa ayam broiler dengan dosis yang berbeda memberikan pengaruh yang sangat nyata $(\mathrm{P}<0,01)$ terhadap prosentase tingkat kematangan telur ikan lele dumbo. Kemudian hasil uji lanjut wilayah berganda duncan menunjukan pula bahwa perlakuan $\mathrm{P}_{4}$ dengan penyuntikan $600 \mathrm{mg}$ kelenjar hipofisa ayam broiler/kg ikan lele dumbo memberikan prosentase tingkat kematangan telur ikan lele dumbo yang sangat nyata $(\mathrm{P}<0,01)$ lebih tinggi bila dibandingkan dengan perlakuan $P_{1} \quad(300 \mathrm{mg}$ kelenjar hipofisa ayam broiler/kg ikan lele dumbo), tetapi nyata lebih tinggi ( $\mathrm{P}<0,05$ ) dari perlakuan $\mathrm{P}_{2}$ (400) $\mathrm{mg}$ kelenjar hipofisa ayam broiler $/ \mathrm{kg}$ ikan lele dumbo), dan tidak berbeda nyata $(\mathrm{P}>0.05)$ dengan perlakuan $P_{3} \quad(500 \mathrm{mg}$ kelenjar hipofisa ayam broiler/kg ikan lele dumbo), P5 (700 mg kelenjar hipofisa ayam broiler $/ \mathrm{kg}$ ikan lele dumbo), dan $\mathrm{P}_{6}$ ( $800 \mathrm{mg}$ kelenjar hipofisa ayam broiler $/ \mathrm{kg}$ ikan lele dumbo). Kemudian uji polinomial orthogonal menunjukan pula bahwa hubungan antara dosis penyuntikan kelenjar hipofisa ayam broiler dengan prosentase tingkat kematangan telur ikan lele dumbo adalah kuadratik dengan persamaan regresinya $: \hat{Y}=47,6784+0,1117$ $X-7,60.10^{-5} X^{2}$, dimana $\hat{Y}=$ prosentase tingkat kematangan telur ikan lele dumbo dugaan, dan X = dosis penyuntikan kelenjar hipofisa ayam broiler (mg kelenjar hipofisa ayam broiler $\mathrm{kg}$ ikan lele dumbo). Dari persamaan regresi ini didapatkan bahwa dosis penyuntikan kelenjar hipofisa ayam broiler yang optimal adalah $734,87 \mathrm{mg}$ kelenjar hipofisa ayam broiler $/ \mathrm{kg}$ berat ikan lele dumbo dengan prosentase ovulasi dugaan maksimal $88,72 \%$. Untuk lebih jelasnya dapat dilihat pada Gambar 3.

Dari Gambar 3 terlihat bahwa semakin tinggi dosis penyuntikan kelenjar hipofisa ayam broiler maka semakin tinggi pula prosentase tingkat kematangan telur ikan lele dumbo. Hal ini disebabkan karena hormon LH yang betasal dari kelenjar hipofisa yang disuntikan pada induk ikan lele dumbo betina berfungsi merangsang sintesa maturation inducing steroid (MIS) dari sel-sel theca folikel. Kemudian MIS inilah yang merangsang proses pematangan telur ikan lele dumbo. 
Tabel 3. Prosentase Tingkat Kematangan Telur Ikan Lele Dumbo Pada Masingmasing Perlakuan Dan Kelompok.

\begin{tabular}{|c|c|c|c|c|c|c|}
\hline \multirow{2}{*}{ Kelompok } & \multicolumn{6}{|c|}{ Perlakuan ( mg kelenjar hipofisu ayam broiler $/ \mathrm{kg}$ ikan lele dumbo) } \\
\hline & $P_{1}(300)$ & $P_{2}(400)$ & $P_{2}(500)$ & $\mathrm{P}_{4}(600)$ & Ps $(700)$ & $P_{6}(800)$ \\
\hline 1 & 72,76 & 79,88 & 86,80 & 90,42 & 93,30 & 88,94 \\
\hline 2 & 77,69 & 77,62 & 90,27 & 94,04 & 89,71 & 84,49 \\
\hline 3 & 70,69 & 84,97 & 82,46 & 85,90 & 87,72 & 92,50 \\
\hline 4 & 74,41 & 81,70 & 84,87 & 89.41 & 85,22 & 86,96 \\
\hline Jumlah & 295,55 & 324,17 & 344,40 & 359.77 & 355,95 & 352,89 \\
\hline Rata-rata & 73,89 an & $81,04^{B 6}$ & $86,10^{\mathrm{Bbe}}$ & $89,94^{\mathrm{Bc}}$ & $88,99^{\mathrm{Bc}}$ & $88.22^{\mathrm{BC}}$ \\
\hline teterangan : & beda ny. & $\begin{array}{l}\text { huruf b } \\
\text { in super } \\
0,05) \text {. }\end{array}$ & yang berbe & 1 menunjur & in berbeda s & gat nyata (f \\
\hline
\end{tabular}

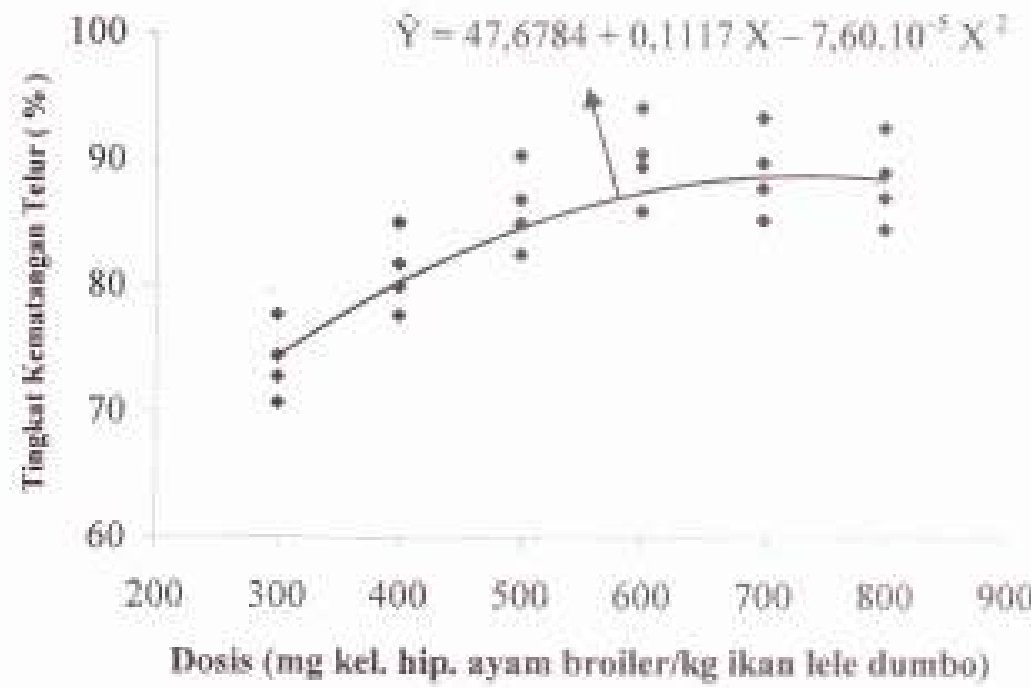

Gambar 3. Grafik hubungan antara dosis penyuntikan kelenjar hipofisa ayam broiler $(\mathrm{X})$ dengan prosentase tingkat kematangan telur ikan lele dumbo $(\mathrm{Y})$.

Tabel 4. Hasil Pengukuran Parameter Kualitas Air Media Pada Bak Pemijahan Ikan Lele Dumbo.

\begin{tabular}{clcc}
\hline No. & \multicolumn{1}{c}{ Parameter } & Satuan & Hasil Pengukuran \\
\hline 1. & $\mathrm{Suhu}$ u & $\mathrm{C}$ & $24,5-29,5$ \\
2. Oksigen terlarut $\left(\mathrm{O}_{2}\right)$ & $\mathrm{ppm}$ & $5,23-6,19$ \\
3. & Karbondioksida bebas $\left(\mathrm{CO}_{2}\right)$ & $\mathrm{ppm}$ & $1,76-2,33$ \\
4. Amoniak $\left(\mathrm{NH}_{3}\right)$ & $\mathrm{ppm}$ & $0,008-0,128$ \\
5. Derajat keasaman $(\mathrm{pH})$ & - & $7,25-7,38$ \\
\hline
\end{tabular}


Semakin tinggi hormon I.H yang masuk $\mathrm{ke}$ dalam darah atau tubuh induk ikan lele dumbo melalui penyuntikan kelenjar hipofisa ayam broiler, maka semakin tinggi pula kadar MIS yang dipsoduksi oleh selsel theca folikel, sehingga semakin banyak pula sel telur yang mengalami proses pematangan dan akibatnya prosentase tingkat kematangan telur juga akan semakin tinggi. Seperti yang telah dikemukakan oleh Goetz (1983) dan Stacey (1984) bahwa hormon gonadothropin hipofisa yaitu LH (Luteinizing Hormon) menyebabkan telur mengalami proses pematungan yaitu dengan merangsang sintesa maturation inducing steroid dari selsel theca folikel, Selanjutnya Nagahama (1987) menambahkan pula bahwa bahagian utama dari maturation inducing steroid ini adalah $17 \alpha, 20 \beta$ - dehydroxyprogesteron. Kemudian pada dosis penyuntikan kelenjar hipofisa ayam broiler yang lebih tinggi dari dosis optimal, prosentase ovulasi ikan lele dumbo menurun. Hal ini diduga karena terjadinya over dosis, sehingga menyebabkan keseimbangan kandungan dan kerja hormon di dalam tubuh ikan lele dumbo tergangge yang kemudian menyebabkan terganggunya pula proses pematangan telur ikan lele dumbo yang diperlakukan.

\section{Kualitas Air Media}

Pada Tabel 4 terlihat bahwa keadaan parameter kualitas air media pada bak pemijahan ikan lele dumbo masih memenuhi bersyaratan yang baik. Menurut Susanto (1984), media air yang baik untuk pemijahan ikan lele dumbo adalah air yang mempunyai suhu $25-30^{\circ} \mathrm{C}$, oksigen terlarut minimal 5 ppm, karbondioksida bebas maksimal 12 ppm, amoniak maksimal $0.5 \mathrm{ppm}$ dan derajat keasaman $(\mathrm{pH})$ antara 7,0 -7.5 .

\section{Kesimpulan Dan Saran}

Dari hasil penelitian yang telah dijelaskan di atas, maka dapat ditarik kesimpulan sebagai berikut bahwa penyuntikan ekstraks kelenjar hipofisa ayam broiler dapat mempercepat waktu laten pemijahan, meningkatkan prosentase ovulasi dan tingkat kematangan telur ikan lele dumbo. Dosis penggunaan atau penyuntikasn kelenjar hipofisa ayam broiler yang optimal adalah 743.75 mg kelenjar hipofisa ayam broiler $/ \mathrm{kg}$ ikan lele dumbo.

\section{Daftar Pustaka}

Bardach, J.E., J.H. Ritner and W.O. Mc Larney. 1972. Aquaculture the Farming and Husbandry of Fresh Water and Marine Organism. John Wiley and Sons, New York.

Goetz, F, W, 1983. Hormone Control of Oocyte Final Maturation and Ovulation in Fishes. In : Fish Physiology. By : W,S. Hoar. D.). Randall and E.M. Donalsond. Volume IX B, Academic Press Inc. New York.

Hardjamulia, A dan S. Atmawinata. 1980. Pembiakan dengan Teknik Hipofisasi Ikan Eksotik Mola (Hyphothalmichrhys molitrix) dan Koan (Cienopharyngodon idella Val.). Pewarta L.PPD, Bogor : Hal $1-5$.

Huisman, E.A. 1976. Hatchery and Nursery Operation in Fish 
Culture Management

Agriculture University of Wageningen, Institute of Animal Production Section Fish Culture and Inland Fisheries.

Jones, R.E. 1987. Ovulation : Insights about the Mechanisms Basic on a Comparative Approach. In : Hormones and Reproduction in Fishes, Amphibians and Reptile. By : E.N. David and R.E. Jones. Plenum Press, New York.

Lam, T.J. 1982. Applications of Endocrinology to Fish Culture. Can. J. Fish. Aquat. Sci, 39 : $111-137$.

Matty, A.J. 1985. Fish Endocrinology. Croom Helm and Timber Press, London Sydney - Portland - Oregon.

Nagahama, Y. 1987. Endocrine Control of Docyte Maturation.
In : Amphibians and Reptile. By : E.N. David and R.E. Jones, Plenum Press, New York.

Stacey. N.E. 1984. Control of the Timing of Ovulation by Exogenous and Endogenous Factors, In : Fish Reproduction. By : G.W. Potts and R.J. Wootton. Academic Press, London.

Steel, R.G.D., dan J.A. Torrie. 1989. Prinsip dan Prosedur Statistika Suatu Pendekatan Biometrik. PT Gramedia, Jakarta.

Sturkie, P.D. 1976. Avian Physiology. Third Edition. Springer - Verlag, New York Heidelberg - Berlin.

Sudjana. 1988. Disain dan Analisis Eksperimen. Tarsito, Bandung. Susanto, H. 1984. Budidaya Ikan Lele. Penerbit Kanisius, Yogyakarta

Alamat korespondensi: Ir. Azhar. MS

Jurusan Produksi Temak, Fakultas Peternakan

Universitas Andalas, Kampus Limau Manis, Padang

Telp. 0751-74208 Fax: 0751-71464, HP: 08126797219

Diterima: 22 April 2007, Disetujui: 18 Mei 2007 